\title{
Observaciones críticas sobre el populismo de Ernesto Laclau"
}

\section{Critical Remarks on Ernesto Laclau's Populism}

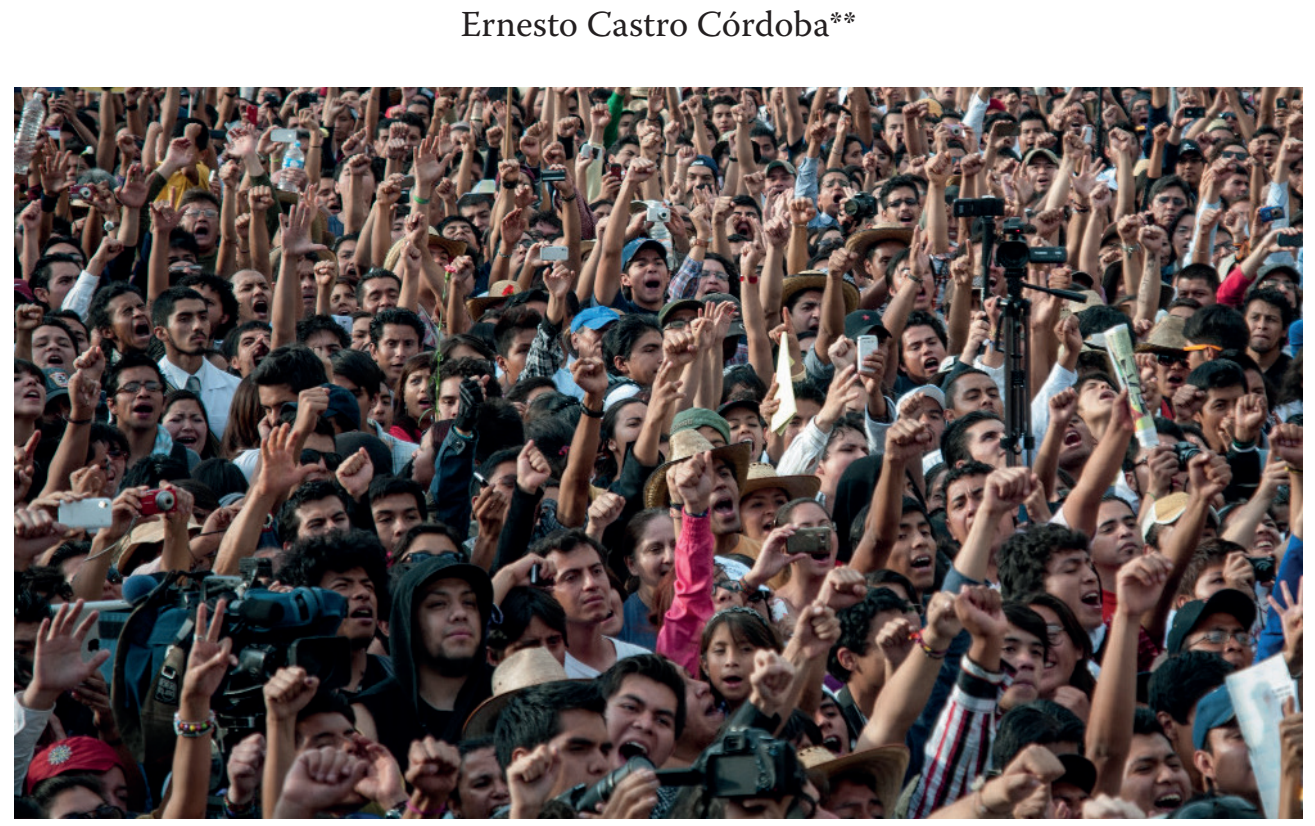

Concepto de populismo. Fuente: https://horizontal.mx/?s=populismo

\section{Resumen}

En este artículo hacemos algunas observaciones críticas sobre el populismo de Ernesto Laclau. Empezamos analizando el primer artículo que publicó Laclau en la New Left Review, sobre el "Cordobazo", el levantamiento social que tuvo lugar en Argentina en 1969. Luego analizamos las inconsistencias de los artículos incluidos en el libro de Laclau, Política e ideología marxista. Por último, analizamos las limitaciones tanto teóricas como prácticas de la obra maestra de Laclau: La razón populista.

Palabrasclave: Ernesto Laclau, populismo, posmarxismo, Argentina, neoliberalismo.

Citar este artículo como: Castro Córdoba, E. (2020). Observaciones críticas sobre el populismo de Ernesto Laclau. Revista Papeles, 12(24), 121-133.

Fecha de recibido: diciembre 10 de 2020. Fecha de aceptado: diciembre 25 de 2020.

* Los textos de este escrito son originales pero no inéditos para la revista Papeles, ha sido publicado por el autor en el siguiente blog https://castracastro.blogspot.com/2014/04/la-politica-efectiva-de-ernesto-laclau. html. Dada la relevancia del mismo el autor ha expresado a la revista Papeles el deseo de incluir este escrito en nuestra publicación y el comité editorial acepto su publicación.

** Filósofo y crítico español. Profesor de filosofía de la Universidad Autónoma de Madrid. Correo electrónico: taunesco@gmail.com 


\begin{abstract}
In this article we make several critical remarks on Ernesto Laclau's populism. We start analyzing the first article published by Laclau in New Left Review, on the "Cordobazo", the social uprising which took place in Argentina in 1969. Then we analyze the inconsistencies of the articles included in Laclau's book, Politics and Ideology in Marxist Theory. Finally, we analyze the theoretical and practical limitations of Laclau's masterpiece On Populist Reason.
\end{abstract}

Keywords: Ernesto Laclau, populism, postmarxism, Argentina, neoliberalism.

En el campo de la grand theory, la comprensión del populismo ha estado asociada, como no podía ser de otro modo, con el nombre de Ernesto Laclau. Por razones obvias, este teórico posmarxista nacido en Argentina y naturalizado en Gran Bretaña ha dedicado buena parte de su carrera académica en solitario a la investigación del fenómeno. El estilo ascético de sus publicaciones no puede ocultar - aunque quizás sublime- la inquietud específica de su nacionalidad de origen. Sus indagaciones sobre el término no solo se acomodan, con todo, a la realidad cambiante de América Latina, sino también a la tendencia filosófica del momento, promulgada desde los salones parisinos. Las voces de Althusser, Gramsci y Lacan han resonado - por ese ordenen sus escritos. Dependiendo de la década en cuestión, la interpelación ideológica, la hegemonía política o la condensación psicoanalítica han sido cruciales para analizar el populismo. No obstante, bajo estos adoquines teóricos, la arena política - y no otra cosa- ha determinado el signo ideológico de sus valoraciones. Pesimista en los 70s, indiferente en los 80 s, optimista en los 90 s, su posición ante el populismo realmente existente ha variado hasta el límite de la incongruencia.

Sus primeras reflexiones sobre el término, en el contexto de la nueva izquierda británica, se remontan a comienzos de los años 70s, con la publicación de un artículo suyo en la New Left Review sobre la junta militar argentina, donde analiza la crisis atravesada por el régimen del general Onganía desde la primavera de 1969, con motivo del levantamiento popular espontáneo acontecido en las ciudades Córdoba y Rosario. Mejor conocido como el Cordobazo, este Mayo argentino no solo reprodujo, sino también profundizó en los elementos de su precedente francés, orientando hacia un camino netamente insurreccional el peculiar solapamiento que tuvo lugar entonces entre radicalismo estudiantil y sindicalismo revolucionario, una confluencia de intereses hasta el momento inédita en Argentina -en 1955, socialistas, comunistas y radicales secundaron el putsch contra Perón-, y cuyo epítome fue la resistencia de la multitud en las calles durante la jornada del 29 de mayo, en una efímera y violenta comuna cordobesa. Según Laclau, esta combustión espontánea de la ciudadanía -encendida por declaraciones contra la dictadura de los mercados impuesta por el FMI- solo resulta comprensible como una respuesta contra las políticas económicas liberales, cuyo manual de reformas para estimular la actividad comercial fue aplicado por el ministro de economía Krieger Vasena, quien derribó los aranceles proteccionistas, devaluó el peso en un 40 por 100, congeló los salarios entre 1966 y 1968, denegando a los sindicatos el derecho a la negociación colectiva. En este contexto, la privatización de los servicios universitarios -seguida por un manifestante asesinado, como de costumbre, 
por la policía-, solo fue la chispa que propició el incendio, suscitando una alianza entre la burguesía estudiantil politizada y los trabajadores de cuello azul, juntos en las barricadas contra los militares. La resistencia armada ciudadana habría consolidado, de este modo, una década de convergencia entre las clases subalternas, quienes habrían finalmente comprendido el significado histórico del peronismo, cuyo mensaje económico sostiene "la necesidad de un crecimiento industrial autónomo basado en la expropiación de la riqueza de la oligarquía, en lugar de la orientación tradicional de la economía argentina hacia la exportación agrícola" (Laclau 1970: 11-12). Así, el Cordobazo recuperaría el espíritu de los descamisados del 17 de octubre contra el bloque oligárquico dominante, cuya estrategia política, desde la formación de Unión Democrática, consistiría en «dejar el Estado en manos de partidos formalmente anti-oligárquicos, a quienes puedan confiar la defensa de sus intereses agrarios más amplios» (Laclau 1970: 4).

Leído en retrospectiva, se impone la lucidez de este artículo, cuyo análisis sintético, pertinente y certero no está exento de objeciones, a pesar de todo. Para empezar, la descripción del campo político argentino en términos dicotómicos, como un combate mitológico entre el liberalismo de los oligarcas y el peronismo de los subalternos, presupone una coherencia ideológica y una continuidad temporal de ambas facciones durante un extenso periodo. Ahora bien, la información recogida en este artículo contradice esta hipótesis por completo. De hecho, la decadencia del imperialismo británico, desde el desenlace de la II GM, no solo sugiere una modificación de la estrategia de dominación imperialista, sino también una modificación de la función que desempeña la economía argentina, hasta entonces orientada hacia la exportación de materias primas, dentro de la división internacional de la producción. Si la segunda mitad del siglo «se caracteriza por las inversiones norteamericanas a gran escala en el sector industrial, que se ha vuelto predominante en la economía como un todo» (Laclau 1970: 6), ¿podemos seguir hablando todavía de la oligarquía rural dominante y las exportaciones del sector primario? En 1964, Onganía sostiene ante los militares de West Point que las fuerzas armadas son «el brazo armado de la Constitución»; dos años después, con la complicidad de los peronistas, disuelve el régimen constitucional y depone el gobierno radical, cuyos principios económicos son la distribución de la renta y el intervencionismo de estado; la dictadura pretoriana posterior, lejos de respetar las formalidades democráticas, lejos de favorecer las exportaciones agrícolas, desmantela el antiguo sistema de partidos y contempla un nuevo impuesto sobre la tierra (Cavarozzi 1983: 100). ¿Dónde quedaron las políticas agrarias y liberales? Durante tres años, agricultores y ganaderos no obtuvieron ningún beneficio con la devaluación monetaria, porque los elevados impuestos sobre las exportaciones incidieron, de forma directa, sobre los precios relativos de sus productos. Si el cierre de la década arrojaba un balance económico favorable - a finales de 1969, un incremento del PIB del 8.9 por 100; en mayo, una tasa anual de inflación de 7 por

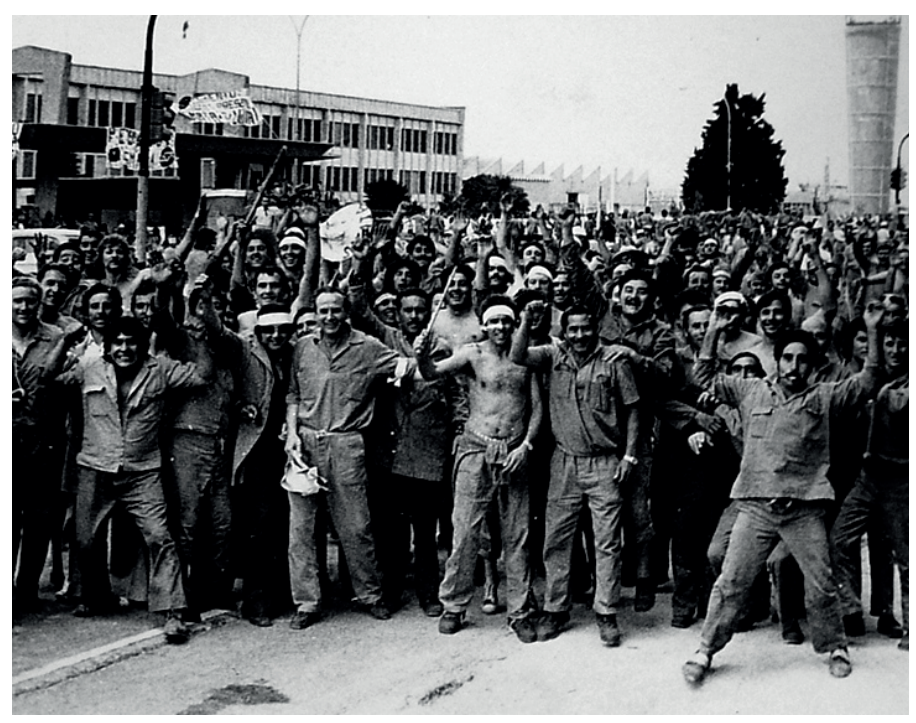

"El Cordobazo", la huelga general que desafió a la dictadura militar de Onganía. Fuente: https://www.telam.com.ar/ 
100; en abril, una reserva de 694 millones de dólares- el incremento exponencial de las inversiones en el sector secundario tuvo toda la culpa (Bethell 2001: 269-270). Mientras tanto, bajo las grandes cifras industriales, la desigual distribución de la riqueza reforzaba el descontento social, generando las condiciones de posibilidad del Cordobazo, toda una insurrección popular urbanita, que identificó a las compañías multinacionales como su adversario. Frente a la insurrección plebeya en las ciudades del interior, no se encontraba entonces el maquillaje constitucional del liberalismo agrario, sino la metralla coercitiva del capitalismo industrial sin rostro humano. Entre octubre de 1945 y mayo de 1969, en lugar de coaliciones irreconciliables, agendas políticas antagónicas y programas económicos incompatibles, encontramos una realidad cambiante, cuya complejidad empírica está estudiada en el artículo, aunque no se extraigan las conclusiones pertinentes.

\section{II.}

Durante la década siguiente, Laclau desarrollará una teoría general del populismo, aplicando las fórmulas teóricas de Althusser sobre la textura del peronismo y del fascismo. El resultado, de nuevo, tiene sus luces y sus sombras. El capítulo «Hacia una teoría del populismo», setenta páginas de puro músculo intelectual, ofrece la mejor versión del marxismo occidental, cuando sus virtudes teóricas, puestas a trabajar sobre la materia

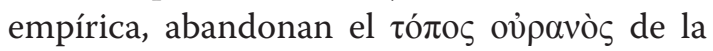
pedantería filosófica. Solo superado por $L a$ crisis de las dictaduras, donde Poulantzas corrige su concepción del fascismo, tomando como referencia la realidad política española, portuguesa y griega del momento, este descenso a la realidad política argentina, brasileña y mexicana constituye el non plus ultra de la «revolución althusseriana» - $\tan$ parnasiana ella.

A la hora de revisar la bibliografía sobre la cuestión, antes de proceder con su propuesta, Laclau certifica la existencia de un consenso teórico infundado entre los expertos precedentes. «Para comprender la conducta política de las clases populares en América Latina en palabras de Gino Germani- es preciso recordar, primero, un rasgo de los países subdesarrollados: la simultaneidad de lo "no contemporáneo"» (Germani 1973: 12). En resumen, la teoría asegura que se producen anacronismos, solapamientos y asincronías durante el periodo de transición entre la comunidad agraria tradicional y la sociedad industrial moderna. En este contexto, el populismo encarna el paradigma del desfase histórico. Su objetivo, la integración política de algunas capas marginales; su método, un programa económico de ideología difusamente reformista; su estrategia, manifestaciones multitudinarias presionando desde abajo. Cómo no, el 17 de octubre es el ejemplo preferido de los teóricos del populismo como un epifenómeno político de las sociedades en desarrollo: campesinos proletarizados del interior que fuerzan la liberación de un coronel filo-fascista mediante una concentración espontánea en las calles, y además deciden por mayoría las elecciones en favor del desarrollismo industrial proteccionista, contra la liberalización económica propugnada por comunistas, socialistas y radicales. Los acontecimientos de 1945 en Argentina reconcilian, de este modo, el retorno de lo reprimido y la prospección del porvenir. Mediante la promoción de una sociedad integrada, según este consenso dominante, el populismo promovería su propia superación; la industrialización del aparato productivo encarnaría su punto de llegada; el ingreso definitivo en la Modernidad extinguiría las pasiones y disuelve a los caudillos. Sin embargo, la actualidad del populismo en las democracias occidentales, articulado en organizaciones y 
en partidos fundamentalistas, desmiente este presunto point of no return. Por este motivo, la respuesta de Laclau a estas concepciones teleológicas sigue siendo válida, porque subraya la posibilidad del eterno retorno populista, con independencia del proceso de modernización atravesado por la sociedad en cuestión. Los jóvenes de extrema derecha europeos, simpatizantes del Partido Popular Suizo, del noruego Partido del Progreso o de los Verdaderos Finlandeses, que obtuvieron porcentajes respectivos en la elecciones de 2012 del 29, el 22 y el 19 por 100 de los votos, deberían suscribir las afirmaciones del posmarxista argentino, cuando sostiene que el carácter aparentemente fundamentalista - de ciertas corrientes arcaizantes en sus fórmulas, refractarias a la mentalidad moderna ilustrada, podría expresar de hecho lo contrario del tradicionalismo; a saber, la negativa a aceptar la legalidad capitalista como propia (Norris 2011).

Ahora bien, ¿qué elementos comparten la Voluntad del Pueblo rusa de 1879, la Hora del Pueblo argentina de 1970 y el Frente Nacional francés de 2002? Su núcleo duro en común, según la teoría althusseriana, estriba en la estructura de sus interpelaciones ideológicas, siendo estas actos lingüísticos performativos que determinan la subjetividad del individuo -o del colectivo, en su defecto-, imponiendo cierta posición social y proyectando cierta identidad política. Este posicionamiento de la mayoría, por contraposición con el entorno y sus agentes, provoca la fragmentación del entramado social, quebrando el sustento de la hegemonía realmente existente. Durante periodos de estabilidad, la formación política dominante asegura sin problemas la consolidación de sus instituciones -así como la fidelidad de la multitud - gracias a la aplicación mecánica de los esquemas de integración convencionales, cuya función consiste en neutralizar la disidencia, bien mediante la incorporación, bien mediante la marginación. Por el contrario, durante un periodo de crisis, la diferencia deviene en contradicción. El excedente no incorporado por el sistema contempla lealtades independientes; los marcadores automáticos de la identidad colectiva desaparecen del horizonte ideológico; comienza una transformación potencialmente destituyente del panorama político. La formación emergente puede consolidar entonces el sistema heredado, aceptando sin reticencias el traspaso generacional de poderes, o bien puede profundizar en ciertas contradicciones, forzando la creación de una realidad alternativa. En esta suerte de encrucijada histórica, siempre aparece el maldito término medio; esto es, la reforma económica parcial, la cínica ideología del posibilismo. En los últimos 200 años, el bonapartismo, primero, y el populismo, después, constituyen paradigmas históricos de esta solución de compromiso. Tanto en el 1951 francés como en el 1945 argentino, la centralización de poderes sobre el ejecutivo y la consulta plebiscitaria de la población fueron — según el análisis marxiano- «la única forma de gobierno posible» entre el descrédito de la burguesía y la emergencia del proletariado (Marx 2010: 34). Entre el liberalismo constitucional y la revolución plebeya, entre el capitalismo imperialista y el socialismo bolchevique, hayamos en ambos casos el camino intermedio del cesarismo democrático - por utilizar la expresión acuñada a comienzos del siglo XX por Laureano Vallenilla, el ideólogo positivista que justificó, recurriendo para ello a los avances científicos recientes, la necesidad histórica y la pertinencia políticas de las

\section{Entre el liberalismo constitucional}

y la revolución plebeya, entre el capitalismo imperialista y el

socialismo bolchevique, hayamos en

ambos casos el camino intermedio del cesarismo democrático. 
el populismo es una variante refinada del clientelismo, cuyos partidos «van siendo progresivamente cooptados por el sistema», cuyo objetivo consiste en «la neutralización política de la posible oposición de nuevos grupos sociales», cuya estrategia se resume en la satisfacción de «demandas populares individualizadas».

repúblicas pretorianas en América Latina, encabezadas por caudillos militares liberales, recelosos de las antiguas camarillas y encumbrados por el sentimiento popular (Vallenilla 1990).

¿El populismo se resume, entonces, en dirigentes autoritarios con actitudes paternalistas hacia el populacho? En este punto, la valoración del argentino no solo es ambigua, sino también mudable. Sobre el potencial transformador del populismo, el lector descubrirá una posición distinta, dependiendo del capítulo que consulte. En un centenar de páginas se amontonan todas las variantes del espectro ideológico, desde el posibilismo conservador hasta el movimiento revolucionario, pasando por el reformismo progresista. Ello demuestra la dificultad que entraña convertir una vaporosa descalificación ideológica en un concepto político articulado. En un momento de Política e ideología, contra las declaraciones optimistas que destacan el revulsivo popular, descubrimos que - para nuestra sorpresa-el populismo es una variante refinada del clientelismo, cuyos partidos «van siendo progresivamente cooptados por el sistema», cuyo objetivo consiste en «la neutralización política de la posible oposición de nuevos grupos sociales», cuya estrategia se resume en la satisfacción de «demandas populares individualizadas» (Laclau 1978:
131). Mientras tanto, en «Hacia una teoría del populismo» se reconoce la existencia de una variante reaccionaria - el populismo de las clases dominantes - altamente represiva para las aspiraciones de discontinuidad, "porque intenta una experiencia más peligrosa que un régimen parlamentario corriente: mientras que el segundo neutraliza simplemente el potencial revolucionario de las interpelaciones populares, el primero trata de desarrollar dicho antagonismo, manteniéndolo dentro de ciertos límites» (Laclau 1978: 203). En «Fascismo e ideología», para terminar, será el jacobinismo quien encarne el momento de transición rupturista, quien vehicule las aspiraciones insatisfechas contra la formación dominante, quien articule con coherencia una sustancia popular que «ya no se presenta con demandas aisladas, ni como una alternativa organizada dentro del sistema, sino como una alternativa política al sistema mismo» (Laclau 1978: 132).

Esta tremenda volatilidad de las manifestaciones populares depende - en principio- de la indefinición constitutiva del pueblo. Esta última expresión no debe leerse, por cierto, en el sentido de la filosofía política moderna. En este contexto, no refiere a la comunidad de ciudadanos que suscriben el contrato social. Evoca, por el contrario, las condiciones de posibilidad de toda confrontación en el interior de la sociedad civil. Los elementos de dominación, las posibilidades de discontinuidad, las estructuras de la hegemonía, todo ello depende del pueblo. Entendido como un recipiente hueco, impone ciertas condiciones de emergencia, ciertos principios de articulación y ciertos parámetros de confrontación entre distintas formaciones políticas; pero eso es todo. La gesticulación populista no conforma una ideología concreta, tan solo el formato de toda oposición, el procedimiento de toda victoria, el mecanismo de toda aglutinación. Desde los fascistas hasta los naródniki, desde la aristocracia hasta el proletariado, el revestimiento formal plebeyo se adapta a 
multitud de propuestas clasistas concretas. Dada la plasticidad constitutiva del fenómeno, no tiene sentido cartografiar las aspiraciones subalternas insatisfechas, en búsqueda de intuiciones espontáneas de emancipación. La única confrontación interesante se encuentra en la instrumentalización partidista de la participación plebeya. En la lucha por la hegemonía, las formaciones políticas irreconciliables deberían, según esta advertencia, esforzarse en pretender que sus reclamaciones particulares representan, en realidad, los intereses de la mayoría silenciosa. A fin de cuentas, la formación política dominante gobierna, como resulta evidente, con la complicidad implícita o con la fidelidad explícita de los dominados. Estos deben tomar conciencia de su situación dentro del entramado de relaciones sociales para reclamar una distribución diferente de los recursos tanto intelectuales como materiales. No obstante, este despertar solo puede acontecer desde fuera.

Sin embargo, para desgracia de la volatilidad declarada, de la indefinición constitutiva y de absorción incompleta, el pueblo no es un colador prêt-à-porter para la resolución de demandas exógenas - tampoco un embalaje del progreso social o una tabula rasa de la lucha de clases. Las clases subalternas tienen su agenda política independiente, no siempre permeable a las apropiaciones partidistas desde fuera. Construida desde abajo, la memoria colectiva solo reconoce la autoridad de ciertas tradiciones culturales, solo responde a ciertos protocolos de organización política. El imaginario popular, en resumen, no se encuentra en estado vegetativo. Laclau bautiza como 'democrática' esta identidad política colectiva. Una expresión equívoca pero acertada: equivoca porque sugiere un compromiso ahistórico con la democracia, cuando esta ha gozado mucho tiempo de mala fama, también entre los subalternos; acertada porque la confrontación entre dominantes y dominados ha propiciado todas las conquistas asociadas con ella. Mitos como la subyugación monárquica normanda, el parlamentarismo anglosajón olvidado o los derechos inalienables del free-born englishman, tan importantes en la democratización del sistema monárquico británico -inicialmente autárquico, posteriormente constitucional y actualmente parlamentario-, validan esta identificación entre inclusión democrática y resistencia subalterna. Por otro lado, la correlación de fuerzas numéricas entre dominantes y dominados no solo justifica la pertinencia de este compromiso histórico, sino que termina asociando muchas demandas paralelas a la causa democrática, como demuestra la incorporación -entre sus apretadas filas- del movimiento sufragista durante el siglo XIX o del proceso descolonizador durante el XX. En este punto, sobre la historia de los sistemas democráticos, Laclau desmantela el concepto de «democracia liberal burguesa», valorando en su justa medida los regímenes constitucionales parlamentarios. También desarma la estrategia revolucionaria antidemocrática, recordando los errores comunistas durante el Tercer Periodo (1928-1935), cuando los comunistas sostuvieron con la socialdemocracia gobernante una oposición bastante improductiva para la izquierda. «Sostener la necesidad de un frente democrático y afirmar al mismo tiempo el carácter burgués de las banderas democráticas solo puede conducir a una desviación de derechas» (Laclau 1978: 159), sostiene el argentino.

Por el contrario, en nuestra concepción, la extensión real del ejercicio de la democracia y la producción de sujetos populares crecientemente hegemónicos constituyen dos aspectos del mismo proceso. El avance hacia la democracia real es una larga marcha que solo será completada con la eliminación de la explotación de clase» (Laclau, 1978, 121-122).

En resumen, la democracia siempre será algo más que libertades negativas y derechos formales. Pero nunca nada menos que eso. 
Con todo, Laclau no parece haber aprendido de los errores de la III Internacional. La mentalidad clase contra clase permanece todavía en su pensamiento. Basta con revisar sus afirmaciones para descubrir el punto de incoherencia. La riqueza empírica no concuerda con el abstracto formalismo; la pluralidad de fenómenos desborda los canales de la teoría; los movimientos populistas no responden ante la interpelación ideológica de Althusser. Si el populismo «comienza en el punto en que los elementos populardemocráticos se presentan como opción antagónica frente a la ideología del bloque dominante», si las aspiraciones democráticas «representan la cristalización ideológica de la resistencia frente a la opresión en general», si las tradiciones plebeyas conforman «un marco estructural de referencia más estable» (Laclau 1978: 194), ¿cómo puede decirse entonces que «no hay un discurso popular-democrático como tal» y que «la ideología democrática sólo existe articulada como momento abstracto de un discurso de clase» (Laclau 1978: 199)? Más adelante, nuestro autor vuelve a reconocer que el pueblo «no logra ser totalmente absorbido por ningún discurso de clase» $\mathrm{y}$ que «el campo ideológico presenta siempre una cierta apertura y su estructuración no es nunca completa» (Laclau 1978: 229), pero no infiere las conclusiones pertinentes. De nuevo, prefiere ignorar las normas más elementales de la lógica, antes de abandonar la dogmática cantinela althusseriana.

Este desfase ente los flamantes axiomas de la teoría y la enredada evidencia empírica termina pasando factura en el análisis del populismo como ocurrencia histórica concreta. Así, el estudio del peronismo -ejemplo privilegiado de investigación - se sostiene sobre un conjunto de premisas un tanto arbitrarias, cuya congruencia con la realidad histórica no compone una verdadera explicación; más bien expresa una coincidencia por analogía. Todas las características imputadas sobre el movimiento encuentran alguna suerte de contraejemplo. La abundancia de pruebas refutatorias demuestra la elevada plasticidad del movimiento en comparación con los rígidos esquemas interpretativos. Según estos esquemas, el peronismo conciliaría - entre otras cosas- el industrialismo proteccionista y el nacionalismo antieuropeísta. Sin embargo, el programa electoral de 1973 contradice estas atribuciones por completo: en política interior, un incremento de las inversiones en el sector primario, conforme a la situación económica internacional, marcada por una demanda insatisfecha de materias primas; en política exterior, una promoción de la unificación continental, siguiendo el modelo de integración europea, como reacción ante la hegemonía yanqui. Sea como fuere, Laclau remacha con insistencia la radicalidad del peronismo, sus «contenidos ideológicos antiliberales» y su «política anti statu quo». De este modo, termina elaborando un retrato coherente del movimiento, a costa de ignorar muchas declaraciones del fundador. Las entrevistas y conferencias referidas corresponden -qué duda cabe- con las hostilidades de 1946: basta con recordar la amenaza liberal de un desembarco de los aliados en Buenos Aires o la dicotomía de los lemas de campaña («Branden o Perón» \& «Tamborini o Hitler») para reconstruir el paisaje de discordia. Ahora bien, este ambiente de hostilidades no concuerda con las promesas de reconciliación suscitadas por el peronismo en los '70. El 8 de noviembre de 1973, Perón pronuncia la conferencia de su investidura presidencial, recalcando su compromiso con un gobierno de excepción, subrayando el proyecto de una unión nacional, fomentando la inversión de capitales extranjeros en el país, ofreciendo en resumen - una mano amiga a la oposición. «Por el bien de mi patria, quisiera que mis enemigos se convenciesen de que mi actitud no solo es humana, sino que es conservadora, en la noble acepción del vocablo» (de Ipola 1987: 145). ¿Dónde se encuentra aquí la ideología antiliberal y la política antagonista? 
Asimismo, el análisis del fascismo incurre en distorsiones similares. Una vez más, un enfoque histórico parcial y un rigor analítico excesivo terminan arruinando una propuesta inicial bastante sugerente. Para empezar, el argentino formula una batería de objeciones contra las indagaciones precedentes que se pueden acomodar sin problemas a su propia hipótesis de trabajo. Así, comienza observando algunos defectos de las explicaciones psicosociales, que interpretan el fascismo como una perturbación moral transitoria, para terminar recurriendo a la dichosa interpelación ideológica, cuyos rudimentos científicos provienen, en último término, del psicoanálisis —el mismo que permite parlotear del fetichismo masoquista de las masas y cosas similares. Sin embargo, el esfuerzo del argentino por contrastar el instrumental analítico, por comprender la concatenación estructural de los sucesos, supera con mucho los ensayos de sus predecesores -incluido Poulantzas, cuyo Fascismo e ideología estudia la decadencia de la República de Weimar mediante paralelismos peregrinos entre ideologías y clases sociales (v.gr.: proletariado $=$ marxismo-leninismo, burguesía $=$ liberalismo, etcétera). Contra este impreciso esquema analítico, Laclau verbaliza una observación rimbombante -en efecto- pero también devastadora: «la adjudicación de una pertenencia de clase a los elementos de las ideologías concretas responde a un procedimiento puramente arbitrario que, como veremos, no solo no construye teóricamente su objeto, sino que, por el contrario, supone su conocimiento empírico y opera taxonómicamente sobre este conocimiento» (Laclau 1978: 109). Para desgracia del argentino, esta misma réplica — solo que invertidase puede exponer contra su examen. La concepción populista del fascismo incurre en la estafa filosófica por excelencia, que consiste en imaginar desde el palacio cristalino de la teoría los sujetos colectivos que intervienen en la historia, recurriendo para ello a expresiones rocambolescas, ciertamente

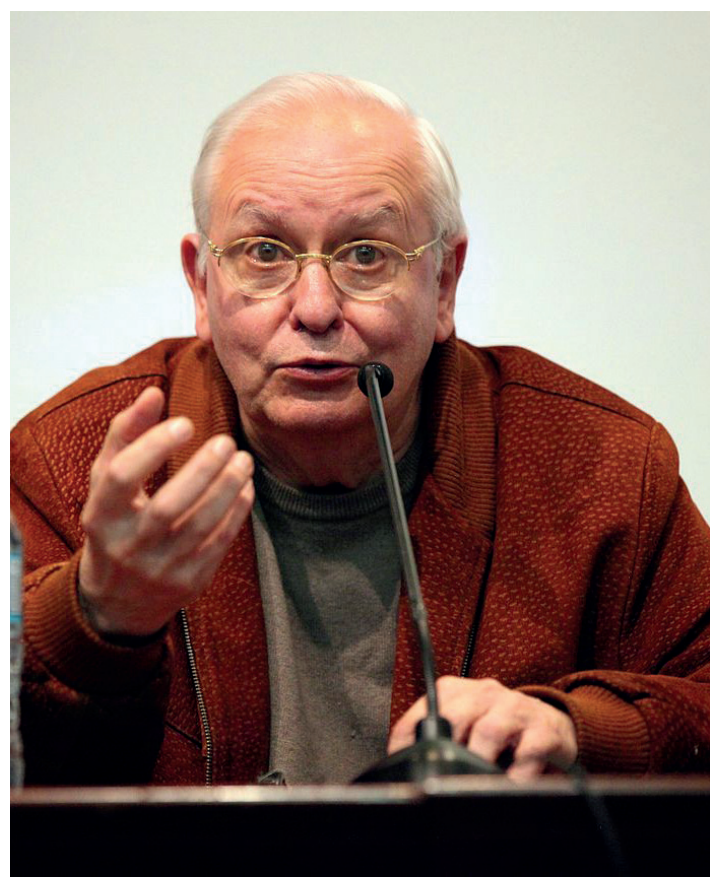

Ernesto Laclau Fuente: wikipedia.org

epatantes, pero sin ninguna correlación con los grupos sociales que - en este caso- convivieron durante el periodo de entreguerras. Ante nuestros ojos se sucede, para nuestra estupefacción, una retahíla de aberraciones sociológicas, tales como la «pequeña burguesía jacobinizada» - un vocablo formidable que sintetiza lo mejor de cada casa: por un lado, el improperio preferido del marxismo panfletario; por otro lado, una corriente política sacada de contexto; en resumen, una coartada perfecta para suspender la investigación. Con esta elegancia, el argentino reproduce los prejuicios convencionales sobre la composición clasista del fascismo, empaquetando bajo el mismo embalaje pequeño-burgués a los pequeños comerciantes y a los trabajadores móviles, reduciendo el ascenso de la extrema derecha en Europa a un subproducto de los errores tácticos de la clase obrera, ignorando la elevada fragmentación ideológica de los grupos sociales durante el periodo de entreguerras (hasta 1934, dos tercios de las SA provenían de la clase trabajadora [Payne 2001: 
69]), tomándose el derecho de interpelar —en último término- a las formaciones políticas del momento, para instruirlas sobre sus deberes y sus destinos, montando un aburrido sermón sobre estrategia revolucionaria, todo ello desde la cátedra retrospectiva de la Historia. Cuando Laclau proclama que el proletariado «hubiera debido presentarse como la fuerza que conduciría las luchas históricas del pueblo alemán a su conclusión y al socialismo como su consumación [...] y hubiera debido hacer un llamamiento a todos los sectores populares que condensara en símbolos ideológicos comunes nacionalismo, socialismo y democracia» (Laclau 1978: 147), quizás ignora el contenido del Programa de Erfurt, conforme a cuyos principios el Partido Socialdemócrata contribuyó a encauzar la trayectoria de Alemania, refrendando patrióticamente los presupuestos militares en 1914, formando amplias coaliciones democráticas desde 1918. Frente a este «reduccionismo clasista», frente a este "extremismo corporativista», frente a este «sindicalismo economicista», la alternativa no parece demasiado halagüeña. «La socialdemocracia contemporánea ha superado - según el encomio del argentino- la mentalidad de grupo de presión del viejo socialismo mediante su transformación en un partido burgués como los otros» (Laclau 1978: 158). Entonces, ¿de esto hablamos cuando hablamos de izquierda?

\section{III}

La publicación de La razón populista marca un final de partida. Entre 1977 y 2004, ¿qué cosas han cambiado? En primer lugar, se ha producido un desplazamiento de los referentes intelectuales. La impronta indiscutible del galomarxismo ha sido sustituida por un conjunto de analogías formales de variada procedencia académica. Todas las disciplinas utilizadas durante la exposición, desde el psicoanálisis hasta los estudios de retórica, concurren -mediante exégesis

\section{Solo el populismo es político, porque}

solo él simplifica la multiplicidad

de diferencias realmente existentes

en una hostilidad declarada, solo

él cuestiona la estructura completa

de las diferencias económicas

y sociopolíticas, solo él -en

resumidas cuentas - involucra una

definición alternativa del mundo

social llamado 'pueblo'. compatibles- a la mejor comprensión del fenómeno. De este modo, la interpelación ideológica pasa el testigo a la condensación, a la equivalencia y a la sinécdoque, con resultados muy productivos. Sostenidas en paralelo, estas aproximaciones conforman, en términos relativos, una descripción mucho más detallada - tanto de la génesis como de la estructura- del populismo. Bajo los tecnicismos y los diagramas, sin embargo, el armazón analítico original permanece inalterado. Si las demandas insatisfechas se articulan mediante cadenas equivalenciales o mediante cadenas diferenciales; si las identidades subalternas se condensan en significantes flotantes o en significantes vacíos; si los movimientos populares se confrontan con oposiciones dialécticas o con exterioridades constitutivas; si las formaciones hegemónicas se enseñorean de la universalidad efectiva o de la mítica totalidad ausente: todas estas minucias terminológicas componen una carnaza de primer orden para las disputas escolásticas de nuestro tiempo, por supuesto. Que la apasionada confrontación entre charlatanes tiene su interés, ello puede mostrarse mediante un repaso de los interrogantes 
principales y de las respuestas ofrecidas -en cada ocasión- por el argentino. Por ejemplo, ¿cuánto de vacío - preguntaba Butler- está el lugar vacío? Solución: «La vacuidad, en lo que al lugar se refiere, no significa simplemente vacio en su sentido literal; por el contrario, hay vacuidad porque ella apunta a la plenitud ausente. Vacuidad y plenitud son, de hecho, sinónimos [sic]» (Laclau 2005: 214). Sea como fuere, estas divergencias bizantinas no modifican - como decimos- la propuesta de investigación empírica principal. El populismo continúa siendo un proceso para la aglutinación de mayorías sociales, que sintetiza aspiraciones insatisfechas y las proyecta sobre una formación política emergente, encabezada por un líder carismático, quien promete defender el interés general contra los enemigos de la mayoría.

Además, los compromisos filosóficos con el psicoanálisis lacaniano conducen a una extrapolación indebida de los estudios concretos, a una generalización fraudulenta de las pretensiones explicativas, a una ontologización infumable del esquema propuesto. Dicho en castellano, Laclau sugiere que su análisis comprende todo. Estos delirios de grandeza, ¿qué tipo de teorías presuponen? En primer lugar, una teoría diferencial del lenguaje, que sostiene que el contenido semántico de un término singular no depende de la expresión lingüística, el individuo denotado y la relación entre ambos; el significado, por el contrario, consiste en las diferencias existentes dentro del propio lenguaje, sin ninguna referencia a la «realidad externa». En segundo lugar, una teoría agónica de la sociedad que (i) proyecta este esquema lingüístico sobre la estructura profunda del mundo social; (ii) considera que la sociedad funciona mediante la conversión de diferencias en hostilidades, y viceversa. En tercer lugar, una teoría normativa de lo político que (a) no establece ninguna distinción entre lo político y lo social; (b) favorece las hostilidades sociopolíticas que versan sobre la propia estructura de las diferencias. Según estas premisas, solo el populismo es político, porque solo él simplifica la multiplicidad de diferencias realmente existentes en una hostilidad declarada, solo él cuestiona la estructura completa de las diferencias económicas y sociopolíticas, solo él -en resumidas cuentas- involucra una definición alternativa del mundo social llamado 'pueblo'. Frente a la autenticidad incontrovertible del populismo nos encontramos con la aburrida administración institucional, entendida como «sedimento social» o «muerte política», en cuanto satisface las demandas singulares mediante procedimientos estandarizados de distribución, en cuanto conforma un cuerpo de funcionarios especializados y deslinda la política de la sociedad civil, en cuanto reconoce la legitimidad de las esferas no politizadas, en cuanto desmantela la posibilidad del antagonismo y burocratiza los conflictos hasta el infinito.

Así pues, la teoría del populismo se presenta como una investigación fundamental sobre las invariantes estructurales y las condiciones de posibilidad de la política tout court. Sin embargo, los criterios estipulados para la contrastación empírica de esta hipótesis de trabajo resultan tan laxos que, por lo pronto, incluyen declaraciones manifiestamente institucionalistas y excluyen programas explícitamente populistas. En primer lugar, la excesiva importancia concedida sobre el antagonismo como mecanismo de articulación política no permite comprender la gestión de las «contradicciones en el seno del pueblo» dentro de una formación populista victoriosa ${ }^{1}$. En segundo lugar, la oposición

1 Para aclarar esta objeción, podemos consultar el último panfleto publicado por Álvaro García Linera - ex-vicepresidente de Bolivia y posmarxista avanzado- cuyo título - Las tensiones creativas de la revolución. La quinta fase del Proceso de Cambio- promete una historia abreviada del proceso constituyente boliviano y su gobierno de movimientos sociales, todo un modelo de populismo izquierdista bien en- 
entre movilización popular y gerencia burocrática no resiste una contrastación empírica medianamente seria. Los ejemplos ofrecidos por el argentino desmantelan, de hecho, su propia intuición preliminar. Antes de nada, recordemos que el institucionalismo pretende satisfacer todos los intereses de la comunidad política, mientras que el populismo discrimina un conjunto de intereses dotados de una legitimidad preferencial. Así pues, en el primer discurso «todas las diferencias son consideradas igualmente válidas dentro de una totalidad más amplia», mientras que el segundo «una frontera de exclusión divide la sociedad en dos campos» (Laclau 2005: 107). Apliquemos ahora este esquema general sobre el caso empírico del neoliberalismo, que en Reino Unido primero «se presenta como una panacea para lograr una sociedad sin fisuras», luego comienza «a denunciar a los parásitos de la seguridad social» y culmina «con uno de los discursos de división social más agresivos de la historia británica contemporánea» (Laclau 2005: 108, 105). El resultado de esta confrontación es bastante desolador, todo hay que decirlo: la campaña electoral del partido conservador -y su polémico «Labour Isn't Working»- reproduciría el consenso institucional; el gobierno de Margaret Thatcher - y su anodino "There Is No Alternative»supondría una ruptura populista, en cambio. Según este principio, ¿qué hay más populista

tendido, según Laclau. Ahora bien, si abrimos estas páginas, sobre la gestión de las demandas democráticas, ¿qué encontramos? «No existe una propuesta alternativa al de la plurinacionalidad descolonizadora que consolida una única nación estatal en la que conviven múltiples naciones culturales y pueblos». Este compromiso con el reconocimiento democrático de las diferencias, ¿no confronta los axiomas del populismo? «No se tiene otra opción de democratización superior del Estado -continua Linera- que no sea el reconocimiento de múltiples formas plurales de democracia (directa, representativa, comunitaria) y de desconcentración territorial del poder a través de las autonomías» (García Linera ,2011, 10). que la sociedad de dos tercios? En este punto, el problema no es la abundancia de contraejemplos, sino la ausencia o la irrelevancia de los mismos. A fin de cuentas, en cuanto aceptamos el esquema ontológico propuesto, la distinción intuitiva entre populismo y tecnocracia desaparece, porque sociedad, política y populismo se convierten por definición en sinónimos. Ahora bien, ¿cómo explicar el fenómeno de la despolitización? «No todo es político - responde Laclau - porque tenemos muchas formas sociales sedimentadas que han desdibujado las huellas de su institución política originaria» (Laclau 2005: 194). La fragilidad de este argumento ad hoc revela -en último término- la puerta trasera del tinglado político-ontológico-psicoanalítico que tenemos entre manos.

En las últimas páginas de su libro, Laclau se cuelga la medalla de honor a la sobriedad intelectual, porque ha discriminado con cuidado entre cuestiones descriptivas y cuestiones normativas, según él, porque ha resistidolatentación de confundir la vigorizante ocupación del análisis político y la pusilánime ociosidad de la moralina. Sin embargo, la distinción entre despolitización institucional y autenticidad populista presupone -como hemos visto- una discriminación normativa de los mecanismos legítimos de hacer política. Conforme a un conjunto de prejuicios bastante extendidos, Laclau considera intrínsecamente valiosa la discontinuidad, la emergencia y la oposición; por el contrario, contempla la burocracia y la negociación por encima del hombro; solo atribuye el concepto de $l o$ político, en consecuencia, a la confrontación irreductible entre identidades antagónicas. Ahora bien, desde una perspectiva política, la asignación óptima de los recursos, en orden a satisfacer las demandas de una comunidad, quizás sea la tarea más elemental de todas. De hecho, la aglutinación de mayorías sociales puede definirse como la correcta localización de promesas entre los miembros de una formación política emergente. Sin embargo, 
mediante antítesis facilonas y contrastes brutales, que no hacen demasiada justicia con la inteligencia o con los hechos, esta caracterización reduccionista de la política garantiza que la autoridad infalible de la ontología se encuentre - en todo momento- de su parte. El pueblo contra la institución, lo político contra lo policial, y otras tantas disyunciones excluyentes, celebran la dignidad de la movilización, despejan la ambigüedad de la política, evidencian con claridad la distinción entre buenos y malos de la película. A golpe de vade retro systemae, estos discursos reconfortantes confirman nuestros prejuicios sobre la vanidad del mundo. Con todo, no ofrecen un instrumental para analizar la situación.

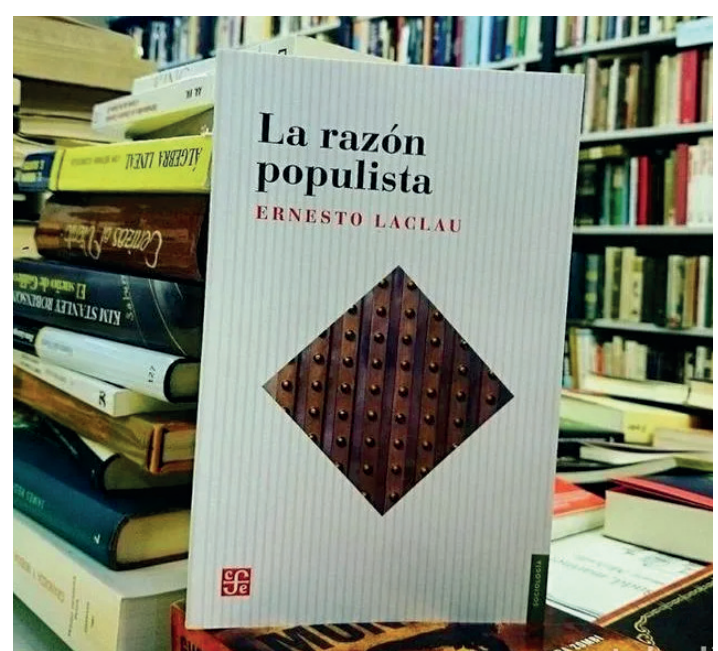

Portada del libro La razón populista de Ernesto Laclau. Fuente: https://es.wikipedia.org/wiki/Ernesto_Laclau

\section{Referencias}

Bethell, Leslie (2001). Historia de la Argentina. Crítica.

Castillo, L. (2020). 51 años de "El Cordobazo", la huelga general que desafió a la dictadura militar de Onganía. Recuperado de https://www.telam.com.ar/ notas/202005/469584-51-anos-de-el-cordobazo-la-huelga-general-que-desafio-ala-dictadura-militar-de-ongania.html

Cavarozzi, Marcelo (1983). Autoritarismo y democracia. Buenos Aires: CEDEAL.

de Ipola, Emilio (1987). Ideología y discurso populista, México: Plaza \& Janés.

García Linera, Álvaro (2011). Las tensiones creativas de la revolución. La quinta fase del Proceso de Cambio. La Paz: Vicepresidencia del Estado Plurinacional.
Germani, Gino (1973). "Democracia representativa y clases populares". En Populismo y contradicciones de clase en Latinoamérica, compilado por Octavio Ianni, México: Era.

Laclau, Ernesto (1970). Argentina - Imperialist Strategy and the May Crisis. New Left Review 1/62: 3-21.

Laclau, Ernesto (1978). Política e ideología en la teoría marxista. Siglo XXI.

Laclau, Ernesto (2005). La razón populista. FCE.

Marx, Karl (2010). "Manifiesto del Consejo General de la Asociación de los Trabajadores sobre la guerra civil en Francia en 1971". En La comuna de Paris, Madrid: Akal.

Norris, Pipa (2011). Derecha radical. Akal.

Payne, Stanley (2001). El fascismo. Alianza.

Vallenilla, Laureano Vallenilla (1990). Cesarismo democrático. Monte Ávila. 